\title{
Effects of Nd on Extrusion Microstructure and Mechanical Properties of ZM21 Magnesium Alloy
}

Quan Li

Chongqing Academy of Science and Technology, Chongqing 401123, China

Jian Peng

Chongqing Academy of Science and Technology, Chongqing 401123, China

College of Materials Science and Engineering, Chongqing University, Chongqing 400044, China

Weibo Zhu

Chongqing Academy of Science and Technology, Chongqing 401123, China

Bin Zeng

Chongqing Academy of Science and Technology, Chongqing 401123, China

College of Materials Science and Engineering, Chongqing University, Chongqing 400044, China

ABSTRACT: In this paper, by adding different amounts of rare earth Nd magnesium alloys in ZM21, ZM21 study of Nd on magnesium alloy thermal processing temperature ductility and plasticity effects and mechanism of the law. The results show that with the increase of Nd content, grain size ZM21 extruded magnesium alloy decreases, the uniformity of grain size is getting better.

KEYWORD: Magnesium Alloy; Extrusion; Microstructure; Mechanical Properties

\section{INTRODUCTION}

Deformation of magnesium alloys in aerospace, automobile, motorcycle, bicycle, and other fields has a very broad application prospects, in with computer, television, cameras, mobile phones and other electronic industry, magnesium alloy has replaced the trend of the plastic shell. In recent years, the use of magnesium alloy rail transport, also become the hot topic of the research application of magnesium alloys, rail vehicle weight reduction, can reduce the load orbit, and can improve the capacity and operation flexibility of locomotive, magnesium alloy used in rail transport, requires both alloy has a certain strength, asked for metal plastic deformation ability is better, to be convenient and efficient plastic deformation (Yu Kun et al, 2005) (Ravi Kumar N V et al, 2013) (J.S. Zhang et al, 2008). Low degree of ZM21 magnesium alloys by alloying and has a good thermal performance, can be used for rapid extrusion. In this paper, through adding different content of rare earth in magnesium alloy ZM21 alloy, the research of trace add Nd hot working plasticity and room temperature plasticity of ZM21 alloy, the influence of provide the basis for development of high plastic deformation of magnesium alloy (Li Wenxian, 2005) (Pan Fusheng et al, 2007) (Ding W J et al, 2012).

\section{EXPERIMENTAL}

Casting water-cooled semi-continuous casting system of ZM21 magnesium alloys with different mass fraction $\mathrm{Nd}$ semi-continuous casting, the chemical composition of the alloy are shown in table 1 . Will cast the ingot in the $12 \mathrm{kw}$ wind circulation box type resistance furnace for $420^{\circ} \mathrm{C} \times 10 \mathrm{~h}$ homogenization annealing treatment, air cooling after the ingot stripping, and extrusion production test in 500 tons of horizontal extrusion machine, extrusion, the blank in the mold at $400{ }^{\circ} \mathrm{C}$ heat preservation in heating furnace $2 \sim 3 \mathrm{~h}$, container set temperature is $390^{\circ} \mathrm{C}$, the extrusion speed is $3.5 \sim 5.5 \mathrm{~m} / \mathrm{min}$. Sample in semicontinuous casting at $1 / 2$ radius cut, corrosion by 5\% nitric acid alcohol solution, use OPTEC MDS organization metallographic microscope observation. Think twice in the new CMT-5105 electronic universal material testing machine room temperature tensile test, the tensile rate of $4 \mathrm{~mm} / \mathrm{min}$.

Table 1 Chemical compositions of experimental alloys (mass fraction, \%)

\begin{tabular}{|l|l|l|l|l|l|l|}
\hline Alloy code & $\mathrm{Si}$ & $\mathrm{Fe}$ & $\mathrm{Zn}$ & $\mathrm{Mn}$ & $\mathrm{Nd}$ & $\mathrm{Mg}$ \\
\hline ZM21(1\#) & 0.0063 & 0.0046 & 2.11 & 0.86 & 0.00 & Bal \\
\hline ZM21+0.1Nd(2\#) & 0.0062 & 0.0038 & 2.05 & 0.88 & 0.09 & Bal \\
\hline ZM21+0.3Nd(3\#) & 0.0061 & 0.0020 & 2.07 & 0.87 & 0.28 & Bal \\
\hline ZM21+0.5Nd(4\#) & 0.0065 & 0.0018 & 2.06 & 0.87 & 0.47 & Bal \\
\hline ZM21+0.7Nd(5\#) & 0.0058 & 0.0016 & 1.98 & 0.88 & 0.68 & Bal \\
\hline
\end{tabular}




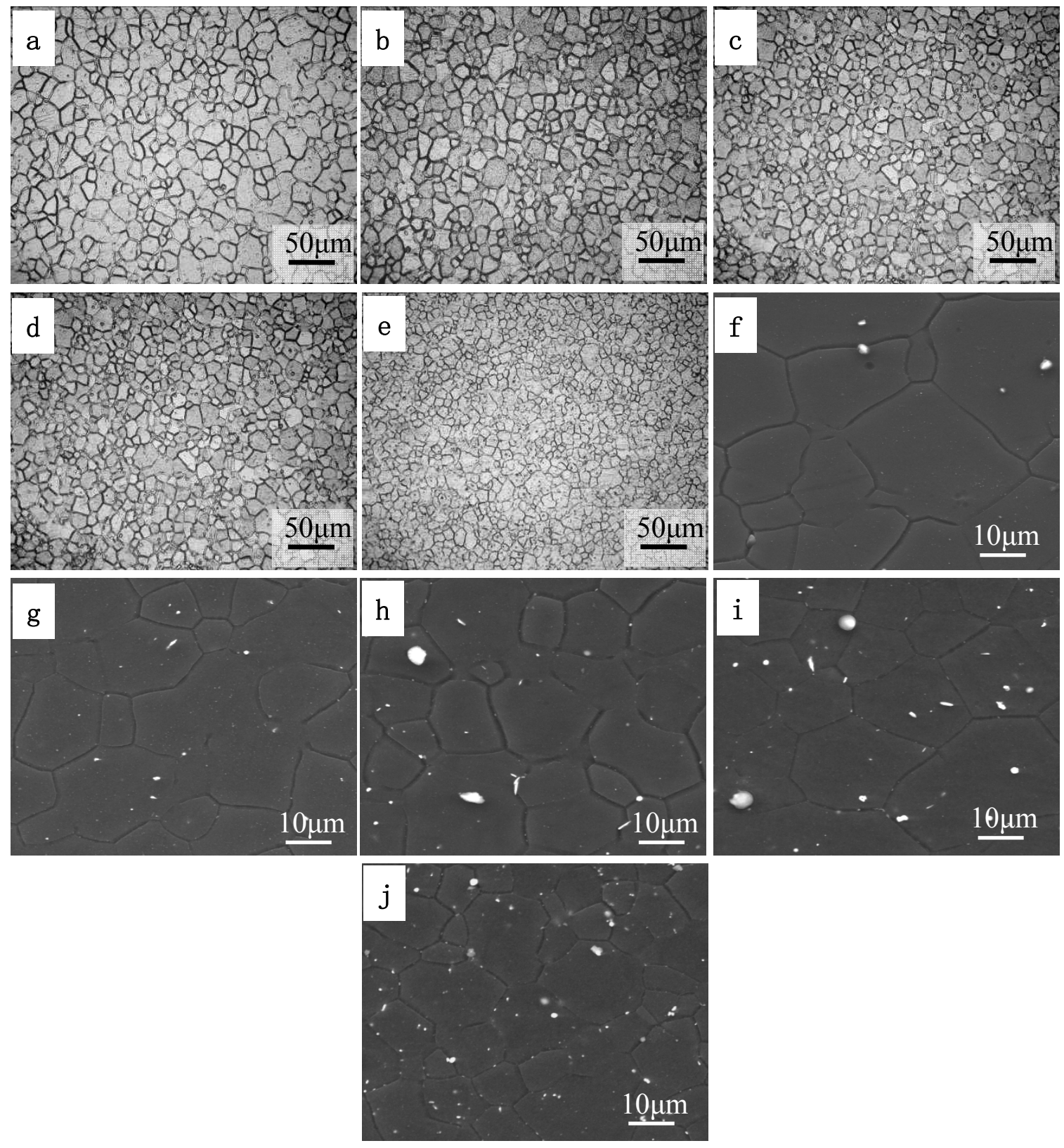

Figure 1 The optical and SEM microstructures of as-extruded alloys

(a): Optical microstructure, ZM21 alloy; (b): Optical microstructure, ZM21+0.1Nd alloy; (c): Optical microstructure, ZM21+0.3Nd alloy; (d): Optical microstructure, ZM21+0.5Nd alloy; (e): Optical microstructure, ZM21+0.7Nd alloy; (f): SEM microstructure, ZM21 alloy; (g): SEM microstructure,ZM21+0.1Nd alloy; (h): SEM microstructure, ZM21+0.3Nd alloy; (i): SEM microstructure, ZM21+0.5Nd alloy; (j): SEM microstructure, $\mathrm{ZM} 21+0.7 \mathrm{Nd}$ alloy

\section{RESULTS AND ANALYSIS}

Figure 1 for alloy extrusion state microstructure and SEM morphology, we know the alloy after extrusion, both the dynamic recrystallization, formed the fine equiaxed crystal grains. With the increase of the content of $\mathrm{Nd}$ squeezed state alloy grain size decreases, the grain size becomes more uniform, the grain size of as-cast alloy 200 microns above elaboration to 30 microns, recrystallization were fully. Through statistics, with the increase of $\mathrm{Nd}$ content, ZM21 alloy extrusion state average grain size from $37 \mathrm{um}$ decreases to $21 \mathrm{um}$. In the early stages, with the increase of $\mathrm{Nd}$ content, alloy average grain size decrease degree is bigger, after the $\mathrm{Nd}$ content increased to $0.3 \%$, with the increase of $\mathrm{Nd}$ content, alloy average grain size decrease the degree of smaller, showed the $\mathrm{Nd}$ to alloy grain refinement effect weakened with the increase of the content. Obviously, the alloying elements is the main reason to grain refining neodymium. In the process of alloy solidification, function composition of super-cooling neodymium, refine as-cast organization before extrusion; In the process of dynamic recrystallization during extrusion, neodymium rare earth elements in solid solution in the substrate than lower alloy axis, conducive to the basal slip system activation, can improve the dynamic recrystallization activation, also 
make the strain distribution more uniform, so that the grain refinement. The length of the error bar that displays ZM21 alloy extrusion state of poor uniformity of grain size, after adding $0.1 \% \mathrm{Nd}$ bar significantly shorter, significantly higher alloy grain size uniformity, with $\mathrm{Nd}$ content continues to increase, the error of bar length is roughly same, alloy grain size uniformity of basically the same.

From figure 1 (f) to (j) alloy extrusion state organization of SEM morphology can be seen that the alloy substrate size distribution on the larger second phase particles, along with the increase of the content of $\mathrm{Nd}$ second phase particles increases gradually. The ZM21 extrusion of the distribution in the alloy is round granule in the second phase of small amount of sizes; ZM21+0.1Nd the second phase in the alloy increased, the elongated needle phase, the average size of particle phase is smaller than ZM21 alloy; ZM21+0.3Nd Alloy continue to grow in the second phase, acicular phase and particle phase are on the rise, some the size of the particle phase is very big; ZM21 alloy than $\mathrm{ZM} 21+0.3 \mathrm{Nd}$ 、 $\mathrm{ZM} 21+0.5 \mathrm{Nd}$ alloy decreases, acicular phase in the granular phase increased, there are more large granular phase; ZM $21+0.7 \mathrm{Nd}$ acicular phase in the alloy, rarely granular phase change very small dispersion.

The mechanical properties of alloy extrusion state as shown in figure 2. Can be seen from the figure 2, and elongation of alloy significantly along with the change of content of $\mathrm{Nd}$, tensile strength and yield strength of the extent of change along with the change of content of $\mathrm{Nd}$ is smaller. After adding $0.1 \% \mathrm{Nd}$, alloy tensile strength, yield strength and elongation is slightly increases, respectively from $248 \mathrm{Mpa}$ to $253 \mathrm{Mpa}, 167 \mathrm{Mpa}$ to $173 \mathrm{Mpa}, 19.1 \%$ to $19.3 \%$; When $\mathrm{Nd}$ content increased to $0.3 \%$, alloy in tensile strength and yield strength, reduce to 235 Mpa and 142 Mpa, respectively below ZM21 alloy extrusion state of tensile strength and yield strength, elongation of the alloy increased to $27.4 \%$, compared to the alloy ZM21 increased by $8.3 \%$; Nd levels continue to increase to $0.5 \%$, the tensile strength and yield strength of the alloy to reduce to $232 \mathrm{Mpa}$ and $141 \mathrm{Mpa}$, reduce the amplitude is small, alloy elongation continue to increase to $32.2 \%$; When a $\mathrm{Nd}$ content reached $0.7 \%$, the largest tensile strength and yield strength of the alloy increased again, increase amplitude is small, increase to $236 \mathrm{Mpa}$ and $146 \mathrm{Mpa}$, respectively is still less than the tensile strength and yield strength of ZM21 alloy, alloy elongation than $\mathrm{ZM} 21+0.5 \mathrm{Nd}$ alloy has slightly lower, at $31.3 \%$. In short, compared to the alloy ZM21, when adding $0.1 \% \mathrm{Nd}$, alloy tensile strength, yield strength and elongation increased slightly, when $\mathrm{Nd}$ content increased to $0.3 \%$, the alloy elongation increased significantly, while the tensile strength and yield strength decrease, adding $0.5 \% \mathrm{Nd}$ alloy minimum tensile strength, yield strength, elongation is the largest.

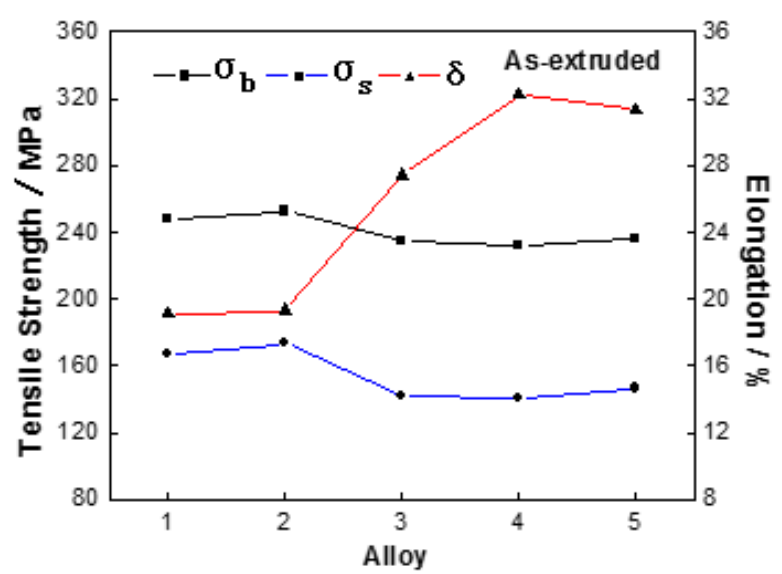

Figure 2 Tensile properties of as-extruded alloys

\section{CONCLUSION}

With the increase of the content of $\mathrm{Nd}$ squeezed state alloy grain size decreases, the grain size becomes more uniform, the grain size of as-cast alloy 200 microns above elaboration to 30 microns, squeezed state alloy grain size with $\mathrm{Nd}$ content increases gradually from $37 \mathrm{um}$ refinement to $21 \mathrm{um}$, the uniformity of the grain size is getting better and better.

Squeezed ZM21 states Nd extension of the alloy increase significantly with the increase of adding amount of neodymium and, when the amount is more than $0.3 \%$ neodymium had small amplitude lower tensile strength, yield strength and hardness increases with the increase of adding amount of neodymium. ZM21+0.5Nd for the plastic of the best in the department of alloy, the tensile strength of 232.1 $\mathrm{MPa}$, the elongation of $32.2 \%$, when the alloy plasticity than without increased by more than $50 \%$.

\section{ACKNOWLEDGEMENTS}

This work is supported by Chongqing " 121 " Project (cstc2014zktjccxBX0078); Chongqing integrated demonstration projects (cstc2013jesf50003).

\section{REFERENCES}

Ding W J, Li D Q, Wang Q D, et al. Microstructure and mechanical properties of hot-rolled $\mathrm{Mg}-\mathrm{Zn}-\mathrm{Nd}-\mathrm{Zr}$ alloys[J]. Materials Science and Engineering A, 2012, 483-484: 228230.

J.S. Zhang, J. Yan, W. Liang, C.X. Xu, C.L. Zhou. Icosahedral quasicrystal phase in $\mathrm{Mg}-\mathrm{Zn}-\mathrm{Nd}$ ternary system [J]. Materials Letters, 62 (2008): 4489-4491. 
Li Wenxian. Magnesium and magnesium alloys[M]. Changsha: Central South University Press, 2005.6.

Pan Fusheng, Han Enhou. High-Performance Wrought Magnesium Alloy and Their Processing Technigues[M]. Beijing: Science Press, 2007.18.

Ravi Kumar N V, Blandin 1 J, Desrayaud C et al. Grain refinement in ZM21 magnesium alloy during thermomechanical processing[J]. Materials Science and Engineering, 2013, A359: 150-157.

Yu Kun, Li Wenxian, Zhang Shijun. Mechanism of Grain Refining by Adding Cerium in $\mathrm{Mg}$ and $\mathrm{Mg}$ Alloys[J]. Rare Metal Materials and Engineering, 2005, Vol.34 (7):10131016. 